\title{
La Enchinchada Digital: Una Propuesta de Innovación Mediada con Tecnologías para el Enriquecimiento del Tradicional Recurso de Enseñanza de las Disciplinas Proyectuales
}

Digital "thumbtacking": A Technology Mediated Innovation Proposal for the

Enrichment of this Traditional Teaching Tool of the Design Disciplines

$>$ Ana Livia Paganini

Universidad de Buenos Aires, Argentina

paganini.ana@gmail.com

> Alejandra Maria de la Paz Bianchi

Universidad de Buenos Aires, Argentina

ampbianchi@fibertel.com.ar
> Adriana Edith Granero

Universidad de Buenos Aires, Argentina

adriana.granero@gmail.com

\begin{abstract}
In design courses in Argentina, "enchinchada" ("thumbtacking") is the name given to the educational tool used for assessment of students' work. Every student's assignment is pinned around the classroom for students to enable, students and teachers to join into a formative dialogue thought observation and reflexion. This work presents the potential of IT in relation to the "enchinchada". It outlines a new use of a digital wall, and recovers and enriches this practice using a free cloud app, Popplet. The experience was carried out at the Universidad de Buenos Aires in 2013 with students of fashion design and textile design.
\end{abstract}

Keywords: Higher Education; Enchinchada; Innovation; Mediated Technology Education; Ubiquity.

\section{Introducción}

Las nuevas tecnologías brindan la oportunidad de trabar relaciones entre espacios de comunicación que antes parecían bastante inconciliables como los contextos formales e informales de educación. Afortunadamente los procesos de aprendizaje imbuidos de los avances de la conectividad y las redes sociales permiten establecer lazos entre diferentes escenarios, extendiéndose más allá del aprendizaje tradicional y sus recursos, hacia espacios ilimitados de tiempo y lugar. El maravilloso sentido del aprendizaje ubicuo que tanto intenta propagar el Dr. Nicholas Burbules. El profesor plantea estimular la investigación de los procesos educativos en aquellos ámbitos en la seguridad de que constituye un proceso fecundo para mejorar la calidad del aprendizaje. Desde donde afirma que la tecnología se relaciona con los distintos movimientos socioculturales que producen transformaciones culturales en sí. Por ello es necesario investigar, probar, reformular y evaluar estas nuevas tecnologías, no como sólo como herramientas de aprendizaje sino como parte de un proceso cultural.

Podemos pensar el internet como espacio creativo, donde construir conocimiento, el espacio para producir sin fronteras. Además con dos ventajas adicionales: la publicidad del conocimiento producido y los nuevos recursos aportados y como expresa Burbules, el potencial incentivo para estudios posteriores. Aparece como un estímulo presente para quienes deseen utilizarlo. Responde al sentido de aprendizaje distribuido, al conocimiento expandido hacia toda la comunidad.

Estas nuevas tecnologías permiten reformular y adaptar la riqueza del aprendizaje tradicional a los nuevos entornos, gene- rando que frente a situaciones problemáticas planteadas, propias del aprendizaje eficaz, se trabaje desde un aprendizaje más social y colaborativo, en el cual se comparte lo que se aprende, se investiga o ya fue incorporado, parece pensar en un aprendizaje socializador, potencializador de los vínculos sociales, todas ellas facetas de la ubicuidad. No sólo tiempo y espacio sino proceso de aprendizaje, es decir cómo, qué y porqué se aprende.

Al tratarse de un proceso social, cobran significancia las actividades de los alumnos por un lado y la motivación que los conduce a ellas. En un contexto social la tarea permite aglutinar, unir al grupo de aprendizaje. Seguramente de ese trabajo en conjunto a través de las redes aparezca la información necesaria para procesar el conocimiento aplicado a la resolución de las situaciones problemáticas propuestas por el docente.

Todo lo mencionado nos remite necesariamente al rol del docente en ese entramado social de comunicación y aprendizaje porque se trata de intervenir en producir y generar conocimientos dentro de comunidades colaborativas. El docente planifica, da las pautas y evalúa los resultados para producir luego los cambios conducentea mejorar el sistema de aprendizaje. De modo que se trata de un proceso cíclico.

\section{Una Propuesta de Innovación Cimentada en la Enchinchada}

La propuesta parte del reconocimiento de la importancia de una práctica tradicional en la enseñanzadelas disciplinas proyectuales: la enchinchada. Guillermina Bertero (2009) expresa que a través de ella se propone la 

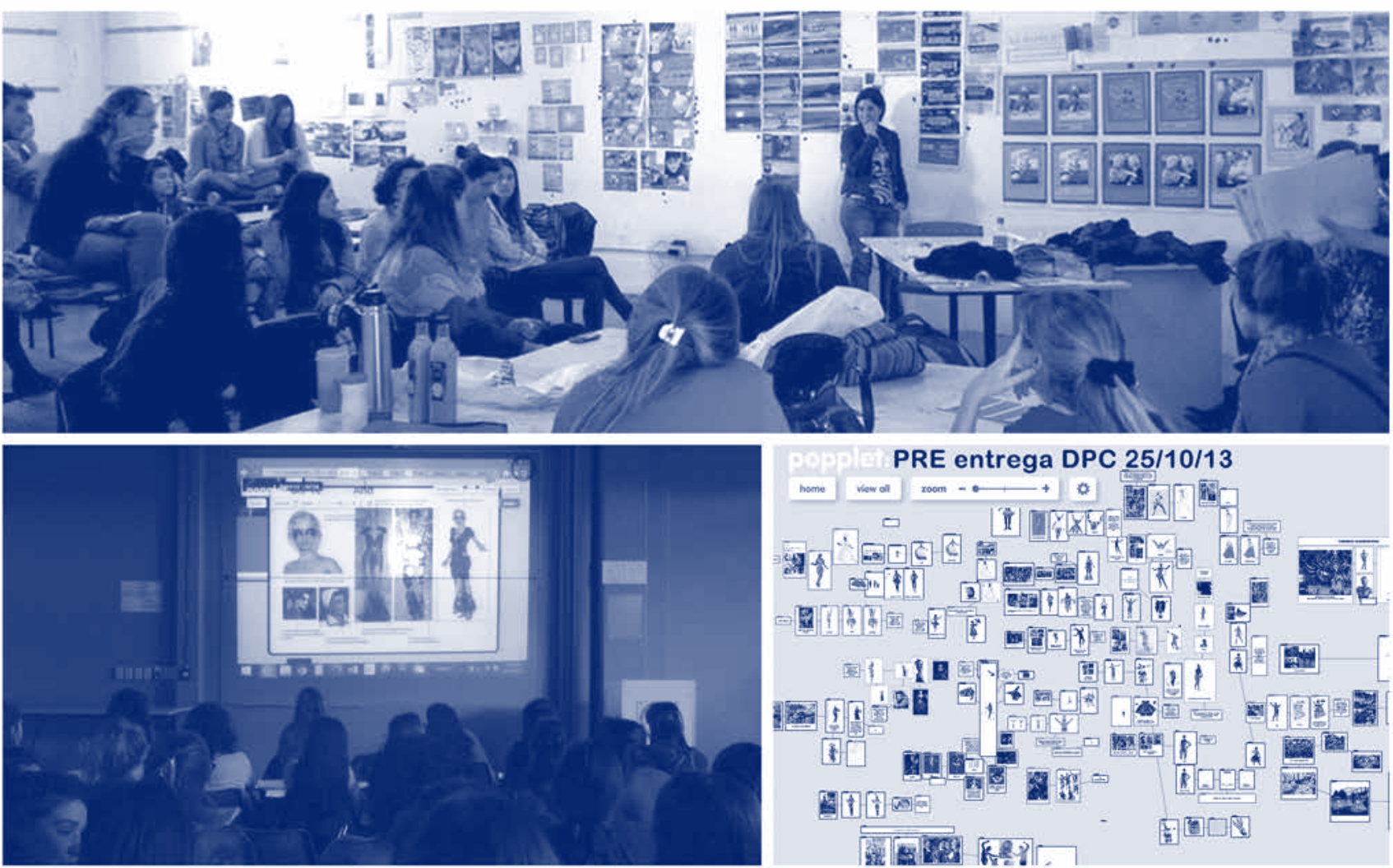

Figura l: Arriba, la enchinchada tradicional en el Taller de Diseño en Comunicación Visual, Taller C. Filpe, FBA, UNLP; abajo izquierda, la enchinchada digital; abajo derecha, captura de pantalla de la enchinchada digital en la pre entrega de Diseño por Computadora, cátedra Hölzel, FADU, UBA. Creado por Ana Paganini.

exposición de la investigación y/o el proyecto de diseño de cada uno de los alumnos para la inmediata reflexión grupal sobre los grandes temas generales de la problemática abordada. En esta exposición la propuesta es defendida por el alumno creador, sus compañeros y docentes preguntan dudas después de la exposición, opinan sobre la propuesta y por último se establece una crítica constructiva. La puesta en común tiene como finalidad la comprensión por parte del alumno que presentó la exposición, las razones y las causas que originan los problemas. Y desde el rol docente, la finalidad de este recurso, es poner en evidencia estas razones y causas para generar un proceso de concientización y para estimular a la indagación de la mayor cantidad de soluciones posibles.

En orden a estas primeras consideraciones la propuesta que hacemos trata de hacer uso de las nuevas tecnologías para potenciar el recurso. El mural digital se plantea como una alternativa libre, abierta y disponible para la creación y distribución gratuita de contenidos que le permite permanecer presente en el tiempo.

Se trata de un proyecto de ejecución que debe intensificarse y probarse, combinado con diferentes recursos, y adaptado a la rama del conocimiento de que se trate, se podrán evaluar los beneficios al generar vínculos enriquecedores para las diferentes comunidades de aprendizaje, tanto para alumnos como para docentes.

\section{El contexto:}

La prueba de campo se operó dentro de la asignatura Diseño por Computadora, materia cuatrimestral electiva de promoción directa de la Carrera de Diseño de Indumentaria y Textil de la Facultad de Arquitectura, Diseño y Urbanismo de la Universidad de Buenos Aires.

El objetivo del desarrollo del ciclo de cursada, es permitir al alumno aprender a desarrollar un proyecto de diseño utilizando la computadora como medio de expresión gráfica, con aplicaciones tridimensionales como bidimensionales en un plano de existencia proyectual digital.

En la materia referida, la disposición del trabajo no es exactamente tipo taller sino más bien un aula en donde se imparten las clases teóricas y cuatro aulas con computadoras en donde se desarrolla la parte práctica y se corrige de manera individual. Y justamente en este punto aparecen cuestiones limitantes para el desarrollo de las clases: por un lado el soporte digital como plano existencial del proyecto, por el otro la masividad y el deseo de incorporar el recurso de exposición colectiva de propuestas.

Se observa entonces la necesidad de usar la tecnología, precisamente porque se trata de diseño por computadora (y no solamente Diseño) pero además porque la enchinchada digital, como la llamaremos, enriquece el trabajo grupal a la par que contribuye con la calidad individual de cada presentación individual. Ello además porque permite la creación de murales con los proyectos de los alumnos, poniendo en juego diferentes competencias como la gráfica, la lingüística y la tecnológica, entre otras. Es decir, se forman nuevas competencias críticas, como plantea Lion, para una ciudadanía digital (Lion, Youtube, 2013). 


\section{El Recurso}

El recurso didáctico que se utilizará para implementar esta renovación, es una aplicación gratuita en la nube que permita crear mapas de contenido (sin jerarquías), que da acceso a la creación de forma colaborativa, cooperativa, multimedia y en tiempo real. Si bien existen diferentes servicios que dan respuesta a estos requisitos, en este caso particular y a modo de ejemplo, se desarrolla sobre Popplet. La misma permite exponer el material de manera grupal, sorteando una de los condicionantes iniciales: permanecer dentro del entorno digital, que la propuesta gráfica de la plataforma no obstaculice la lectura de los proyectos plasmados en ella, que sea posible mantener una relativa privacidad, (similar a la que encontramos en el aula), que se pueda identificar al alumno, que sea gratuita.

En general los profesionales de los campos proyectuales prefieren la visualización a la verbalización. Como plantea el Arq Iglesias (Frigerio, Pescio, \& Piatelli, 2007)., para el diseñador , los sistemas de representación se constituyen en elementos de pre configuración y no solo de representación, en los que se anticipa, se propone, se imagina una transformación de la realidad, constituyendo el plano de existencia utilización durante la gestión proyectual. Para la implementación se requiere un manejo mínimo de un lenguaje gráfico digital, y en el caso particular de la asignatura sobre la que se hace el trabajo de campo, la representación digital es el objeto de investigación y enseñanza en sí misma.

\section{La Innovación}

Puede considerarse que la propuesta de la enchinchada digital innova al estar cimentada en estos murales grupales presenciales, brindando la posibilidad de hacerla desde un ámbito pluricontextual, sin tiempo ni espacio, pero perfilada por las pautas previas, consecuentes y concretas del docente a cargo.

Cada alumno puede enchinchar desde múltiples dispositivos electrónicos, adhiriéndose en algún sector del gran mural, al tiempo va observando la inserción de sus compañeros en ese gran espacio de comunicación llamado mural digital.

Se observó en la experiencia realizada en 2013 que el intercambio es altamente productivo no sólo como pensamiento creativo sino también divergente ${ }^{1}$, basado en esa capacidad de producir muchas y variadas respuestas a una misma situación planteada.

Posteriormente proponemos realizar la reflexión general dentro de un ámbito con accesibilidad colectiva, es decir de todos los grupos que conforman las diferentes comisiones de cátedra y plasmarlo en el documento.

De esta manera, cada alumno aporta y a su vez se enriquece, más aún cuando puede informarse acerca de las correcciones que va haciendo cada docente en los diferentes proyectos.

Normalmente, la etapa de corrección puede ser compleja cuando la cursada es numerosa y es posible escuchar los aportes de los docentes de las distintas comisiones. El alumno, es participe tanto en la presentación de su propuesta particular, como en el análisis de las soluciones propuestas por los demás integrantes del taller. Es

1 DE BONO, Ed, Teoría del Pensamiento Divergente. http://www. youtube.com/watch? $\mathrm{v}=$ Z78aaeJR8no\#t=653 sujeto del aprendizaje autogestionado, y ese aprendizaje se maximiza al permitírsele a la propuesta colectiva (con las observaciones de la corrección) permanecer en el tiempo.

Se plasma así el pensamiento de Robinson ${ }^{2}$ cuando expresa que la mayoría del gran aprendizaje ocurre en grupos donde la colaboración es la fuente del crecimiento. (Robinson, 2008)

Por otro lado, es doblemente beneficioso tanto para el profesor como para los alumnos, ya que ante la ausencia eventual de aquél en el aula presencial, la enchinchada digital representa un excelente medio tutorial para observar y corregir desde múltiples dispositivos y plataformas ${ }^{3}$ tendiendo a posibilitar lo que Pisciltelli denomina Embodiment. (Neri, 2011) Parecería responder al concepto de aprendizaje omnipresente propuesto por el Dr. Burbules. (Burbules, 2011) Permite, como sostiene Lion, pensar en red, en colaboración, como un sistema de retroalimentación permanente (Lion, Pensar en red: metáforas y escenarios, 2012). Verdaderamente es un espacio compartido que se siente como propio pero que no pretende eliminar el contacto presencial de la enchinchada tradicional, sino aportarle a ella el gran significado de la ubicuidad, entre otras potencialidades.

Consideramos que esta incorporación al dispositivo usual de enseñanza potenciará el esfuerzo en torno a la inducción o formación de imágenes permitiendo una apertura enriquecedora desde cada uno de los integrantes hacia todo el conjunto, ya que enriquecerá el conglomerado de información necesaria para el proceso decisorio intencional y creativo del proceso proyectual.

Es un aprendizaje justo a tiempo: que supone aprendizaje con relevancia, significatividad y oportunidad.

Es un aprendizaje relevante, supera ampliamente la enchinchada presencial, permitiendo enlazar trabajos, observar las motivaciones que les dieron origen, facilita el intercambio visual a través del mural, lo cual es una ayuda constante para la dinámica del aula presencial tanto para los alumnos que deben cumplir las pautas establecidas por la cátedra como para la labor docente en orden a analizar sus propuestas, el proceso de elaboración, los ajustes que deben realizarse y los resultados obtenidos. Es aprendizaje que deja en el grupo, huellas visibles de los aprendizajes invisibles, según las palabras de Cristóbal Cobo. (Cobo, 2010)

Es significativo porque permite visualizar las propuestas de cada uno, el nivel de realización de la tarea propuesta por el docente para un determinado grupo de alumnos que cursan la materia en diferentes comisiones. Supone además las correcciones o comentarios de los distintos docentes a cargo. Lo cual da significado específico, valor concreto, a ese gran mural de enchinchada para los alumnos que participan. Representa una delegación de ideas que se documentan y se registran con otros en una red revisitada, reconstruida, interpelada con alto potencial educativo al ser recuperada a través de las diferentes entregas de los alumnos ${ }^{4}$ (Lion, Pensar en red:

2 ROBINSON, Ken. Changing Paradigms http://www.youtube.com/ watch? $=$ Z78aaeJR8no\#t=653

3 PC, MAC, Ipad, Iphone

4 LION, Carina, “Cómo serán? El futuro de la escuela y las nuevas tecnologías”, cap. Pensar en red. Metáforas y Escenarios”, Pensar en Red, pág, 39,. Ed. Prometeo, 2012 

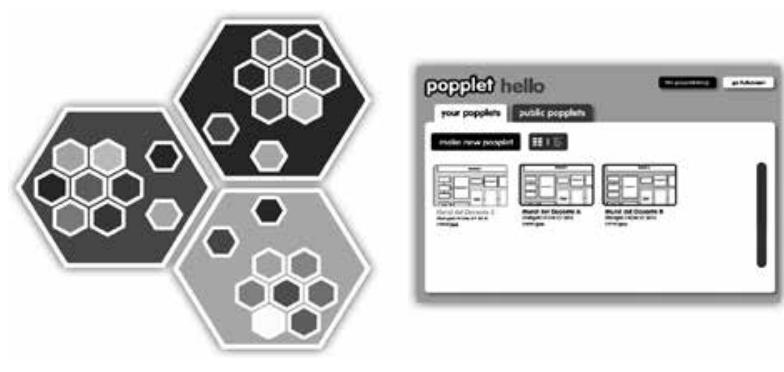

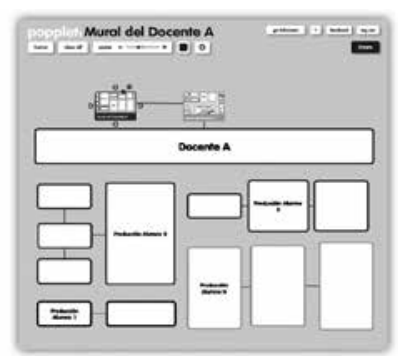

Cuando se establezca el momento de la corrección de la enchinchada, se procederá a verla en conjunto con el proyector de cada aula, o con el dispositivo que cada uno considere o en el aula teórica si es necesario, pero siempre documentando la reflexiones críticas, la defensa del propio trabajo y las virtudes de los trabajos ajenos con el objetivo de potenciar el dialogo y la comprensión de cada propuesta. Sin estas reflexiones, nos quedaremos a mitad de camino, ya que las mismas son las que dan contexto.

\section{Referencias}

Bertero, C. (2009) La enseñanza de la arquitectura: entre la dibujado y lo desdibujado. (pag. 42-46) $1^{\circ}$ ed. Santa Fe. Universidad Nacional del Litoral.

Burbules, N. C. (2011). http://faculty.education.illinois.edu/burbules/videos.html. Obtenido de http://faculty.ed.uiuc.edu/ burbules/videos.html: http://faculty.education.illinois.edu/ burbules/videos.html

Cobo, C. (2010). TedxLaguna. Obtenido de Aprendizaje invisible: ¿Cómo aprender a pesar de la escuela?: http://www.youtube. $\mathrm{com} /$ watch? $=9 \mathrm{E} \_$BH00dkJk

Frigerio, M. d., Pescio, S., \& Piatelli, L. (2007). Acerca de la enseñanza del diseño. Buenos Aires: Nobuko.

Gaite, A. (2012). Didáctica del taller de diseño. Programas, ideas y monografías. Buenos Aires: Nobuko.

Levy, P. (s.f.). Inteligencia Colectiva: por una antropología del ciberespacio. Paris.

Lion, C. (2012). Pensar en red: metáforas y escenarios. En M. Narodowski, \& A. Scialabba, ¿Cómo serán? El futuro de la escuela y las nuevas tecnologías (págs. 29-45). Buenos Aires: Prometeo.

Lion, C. (2013). Youtube. Recuperado el 19 de 02 de 2014, de UBATIC +: http://www.youtube.com/watch?v=o_QTFPdnrjY

Mazzeo, C., \& Romano, A. M. (2007). La enseñanza de las disciplinas proyectuales. Hacia la construcción de una didáctica para la enseñanza superior. Buenos Aires: Nobuko.

Neri, C. (2011). De la inclusión social al cambio educativo, un largo camino a recorrer. Buenos Aires.

Popplet. (2014). Popplet. Nueva York, Nueva York, USA. Obtenido de Popplet: www.popplet.com

Robinson, K. (2008). RSA - Changing Paradigms. Obtenido de Royal Society of Arts: http://www.youtube.com/watch?v=Z78aaeJR8no\#t=653

Salomon, G., Bloberson, T., \& Perkins, D. N. (1992). Coparticipando en el conocimiento: la ampliación de la inteligencia humana con las tecnologías inteligentes. Comunicación, lenguaje y educación, 6-22. 